\title{
Experimental Design Optimization of Filamentous Phage Transfection into Mammalian Cells by Cationic Lipids
}

BioTechniques 28:1202-1213 (June 2000)

\section{Luc Aujame, Delphine Seguin, Carole Droy and Catherine Hessler}

Aventis Pasteur, Marcy l'Etoile, France

\section{INTRODUCTION}

Interest in filamentous phage has in recent years moved from a means of accessing ssDNA for cloning and sequencing (17) to the possibility of presenting peptides or proteins on cellular surfaces (26). This has opened the field of phage-displayed peptide and antibody libraries and selection by panning of biologically interesting molecules $(1,13,20)$. In vivo selection $(2,19)$ suggests that it might be possible to use phage as live vectors for specific cell targeting $(2,15,24)$. Because filamentous phage carry ssDNA, it is not immediately obvious that their entry into cells would lead to efficient expression of genes driven by mammalian promoters. The results of Yokoyama-Kobayashi and Kato (32) indicated that this was the case, whereby whole phage complexed to the lipopolyamine Transfectam (or DEAE-dextran) (31) were effectively transfected into various cell lines leading to the subsequent expression of the gene carried by these phage. In the present study, an experimental methodology was used to determine optimum transfection efficiency in a minimum number of experiments, and its results were compared with those using a more standard strategy.

Experimental design approaches (4) allow researchers to solve specific problems either at an early stage (to determine the influence of various parameters affecting an experiment) or later to optimize the system. While experimental design has been used in other fields $(6,14,18,21,23,25)$, its use in cell or molecular biology has been limited. Two recent papers $(3,7)$ have described the usefulness of experimental design in optimizing PCR conditions. Also, Yin and Carter (30) used an incomplete factorial design and a response surface method to optimize the yield of RNA transcription in an in vitro T7 RNA transcription assay. The uniform shell experimental technique of Doehlert (8) was used by Ganne and Mignot (10) to optimize the expression of factor VIII production in $\mathrm{CHO}$ cells by assessing the effects of two different growth factors, human transferrin and insulin. Here, we have also used a Doehlert matrix to optimize transfection conditions for two different factors: the quantity of phage and lipid. We show that this approach is readily applicable to phage transfection, with an obvious extension to DNA transfection and significant savings both in terms of time and number of experiments. Additionally, we have extended the analysis of transfection to the comparison of different cationic lipids on two cell lines.

\section{MATERIALS AND METHODS}

\section{Plasmid Construction}

pM47. The luciferase gene was amplified from plasmid pGL3-BASIC (Promega, Madison, WI, USA) by PCR and then inserted directly into plasmid pCR3.1 (Invitrogen, Carlsbad, CA, USA) using the manufacturer's instructions. Insertions in the proper orientation were analyzed by digestion with the appropriate restriction enzymes and sequenced to verify the absence of mutations.

pM40. The green fluorescent mentous phage. 
protein (GFP) gene was similarly amplified from pGFP-1 (Clontech Laboratories, Palo Alto, CA, USA) and then inserted into pCR3.1.

\section{Lipids}

Transfectam ${ }^{\circledR}$ was purchased from Promega. TC1-12 was a gift from Dr. Jean Heansler (Formulation Center, Aventis Pasteur). $\gamma$-AP-DLRIE/DOPE or GAP-DLRIE/DOPE (29) was obtained from Vical (San Diego, CA, USA) and RPR120535b (5) from Gerardo Byk (RPR/GENCELL, Vitry, France).

\section{Phage Preparation}

For proper transfection into mammalian cells in the presence of cationic lipids, phage had to be prepared in such a way to ensure the absence of major contaminants, particularly bacterial DNA, which we found interfered with lipid-based transfection. The following protocol was established. Plasmids were transferred to bacterial strain 7118 (Stratagene, La Jolla, CA, USA) for phage stock preparation. From an overnight 2-mL culture from a single colony, a $100-\mathrm{mL}$ or $500-\mathrm{mL}$ culture was grown to an $\mathrm{A}_{600}$ of 0.6 before adding helper phage VCSM13 (about $10^{12} \mathrm{pfu}$ ). After $1 \mathrm{~h}$ at $37^{\circ} \mathrm{C}$, the culture was incubated overnight at $30^{\circ} \mathrm{C}$. Phage were recovered by standard polyethyleneglycol (PEG) precipitation (22) and resuspended in 1 to $5 \mathrm{~mL} 10 \mathrm{mM}$ Tris$\mathrm{HCl}$ ( $\mathrm{pH} 8.0$ ). $\mathrm{MgCl}_{2}$ was added to a final concentration of $0.3 \mathrm{mM}$, followed by DNase (10 U/mL) (Sigma-Aldrich, Saint-Quentin-Fallavier, France). Digestion was maintained for $1-2 \mathrm{~h}$ at room temperature, and the reaction was stopped by the addition of $3 \mathrm{mM}$ EDTA. The absence of contaminating DNA before and after DNase treatment was monitored by gel electrophoresis. Phage were then filter-sterilized by passing through Millex ${ }^{\circledR} 0.45$ - and 0.22- $\mu$ m filters (Millipore, Saint Quentin en Yvelines, France). Titers were determined on competent $71-18$ cells.

\section{Transfection}

CHO (DHFR-) (27) and Cos-7 (12) cells were maintained in $\alpha$-MEM (Life
Technologies, Cergy Pontoise, France) supplemented with $10 \%$ (vol/vol) FCS. One day before transfection, cells were plated into 6 -well plates at $2.5 \times 10^{5}$ cells/well. The next day, cells were washed twice in PBS before adding phage-lipid or DNA-lipid complexes. These were prepared by diluting the chosen amounts of lipid and phage with equal volumes (usually $100 \mu \mathrm{L}$ each) of optiMEM $^{\mathrm{TM}}$ (Life Technologies) without serum. After mixing the phage solution into the lipid, optiMEM was added (for 1-mL total volume) and then added to the cells. The complex was left in contact with the cells for $5 \mathrm{~h}$, before adding $1 \mathrm{~mL} \mathrm{MEM} / 20 \% \mathrm{FCS}$ (v/v) for $48 \mathrm{~h}$.

\section{Luciferase Assay}

Cells were washed once with PBS, trypsinized and centrifuged $400 \times g$. To one-half of the cells was added $400 \mu \mathrm{L}$ lysis buffer [25 mM Tris-Hcl (pH 7.8), 2 mM CDTA, 2 mM DTT, 10\% (vol/ vol) glycerol and $1 \%$ (vol/vol) Triton ${ }^{\circledR}$ $\mathrm{X}-100]$ for $10 \mathrm{~min}$ at room temperature. Cells were then centrifuged for $10 \mathrm{~min}$ at full speed (14000 rpm) in an Eppendorf 5415C (Hamburg, Germany) microcentrifuge to spin down cell debris.

Luciferase activity was monitored in a Lumat LB9501 luminometer (Berthold, Bad Wildbad, Germany) in the presence of substrate $[470 \mu \mathrm{M}$ luciferin, $270 \mu \mathrm{M}$ coenzyme A, $530 \mu \mathrm{M}$ ATP diluted in $20 \mathrm{mM}$ Tricine, 53.5 $\mu \mathrm{M}$ magnesium carbonate hydroxyde, $2.67 \mathrm{mM}$ EDTA and $33.3 \mathrm{mM}$ DTT].

\section{Protein Analysis}

The other half of the cells recovered in $100 \mu \mathrm{L}$ distilled water as above was used to assay for total protein concentration by a BCA protein assay (Pierce Chemical, Rockford, IL, USA) according to the manufacturer's instructions. Analysis was peformed on a $v$ MAX kinetic microplate reader (Molecular Devices, Sunnyvale, CA, USA).

\section{FACS Analysis}

pGFP-transfected or control cells, resuspended in PBS, were analyzed for fluorescence emission at $525 \mathrm{~nm}$ on a Beckton Dickinson (Franklin Lakes, 
NJ, USA) FACScan ${ }^{\mathrm{TM}}$ flow cytometer $(25-\mathrm{mW}$ laser at $488 \mathrm{~nm})$.

\section{Experimental Design}

An experimental design (Table 1) proposed by Doehlert (8) was used to determine optimal conditions with two quantitative variables: phage and lipid. When the extreme values of the parameters are coded -1 and +1 (Table 1 ), the matrix makes it possible to explore a circular domain of radius 1 . One major advantage is that the matrix limits experiments to $\mathrm{N}=\mathrm{K}^{2}+\mathrm{K}+1$ data points (where $\mathrm{N}$ is the number of experiments and $\mathrm{K}$ the number of variables) distributed evenly within the chosen domain space. Another advantage of this approach is that it is possible to easily extend the field of study (should it lie outside the optimum) to a neighboring space by taking the adjacent network because of the complementarity of the rhombic shell domains. The response is modelized by a second order polynomial equation which for two variables (X and $Y$ ) is: $Y=\beta_{0}+\beta_{1} X_{1}+\beta_{2} X_{2}$ $+\beta_{11} X_{1}^{2}+\beta_{22} X_{2}^{2}+\beta_{12} X_{1} X_{2}+\varepsilon$, where $\beta_{\mathrm{i}}$ are coefficients corresponding to the relative influence of each variable on the response and $\varepsilon$ the experimental error. The corresponding estimated model is described by the equation: $\hat{y}=b_{0}+b_{1} x_{1}+b_{2} x_{2}+b_{11} x_{1}^{2}$ $+b_{22} x_{2}^{2}+b_{12} x_{1} x_{2}$. Once validated, the model makes it possible to predict the evolution of the response at any point in the domain. Generally, only the central point is repeated three times-for variability assessments sufficient to test the significance of the $\beta_{\mathrm{i}}$ coefficients and to ensure a uniform precision over the entire domain.

Analysis of variance is carried out to test both the significance of the regression and to estimate whether the model adequately describes the observed data. To test the significance of the regression, an F-ratio is obtained by dividing the mean square of the regression by the residual mean square. The corresponding $P$-value must then be less than 0.05 to ensure significance. The lack-of-fit test is performed by comparing with an $F$ test the variability of the model residuals to the variability between observations at replicate values. If the corresponding $P$-value is less than 0.10 , then there is a significant lack-of-fit of the model at the $90 \%$ confidence level. Furthermore, theoretical $\mathrm{Y}$ values are also compared with the experimental ones through the examination of standardized residuals. Lastly, the fit between

values calculated by the model and determined experimentally is represented by an $\mathrm{R}^{2}$ expressed as a percentage $\left[\mathrm{R}^{2 \%}=\right.$ (variation explained by the model/total variation) $\times 100)]$. After validating the model, the significance of

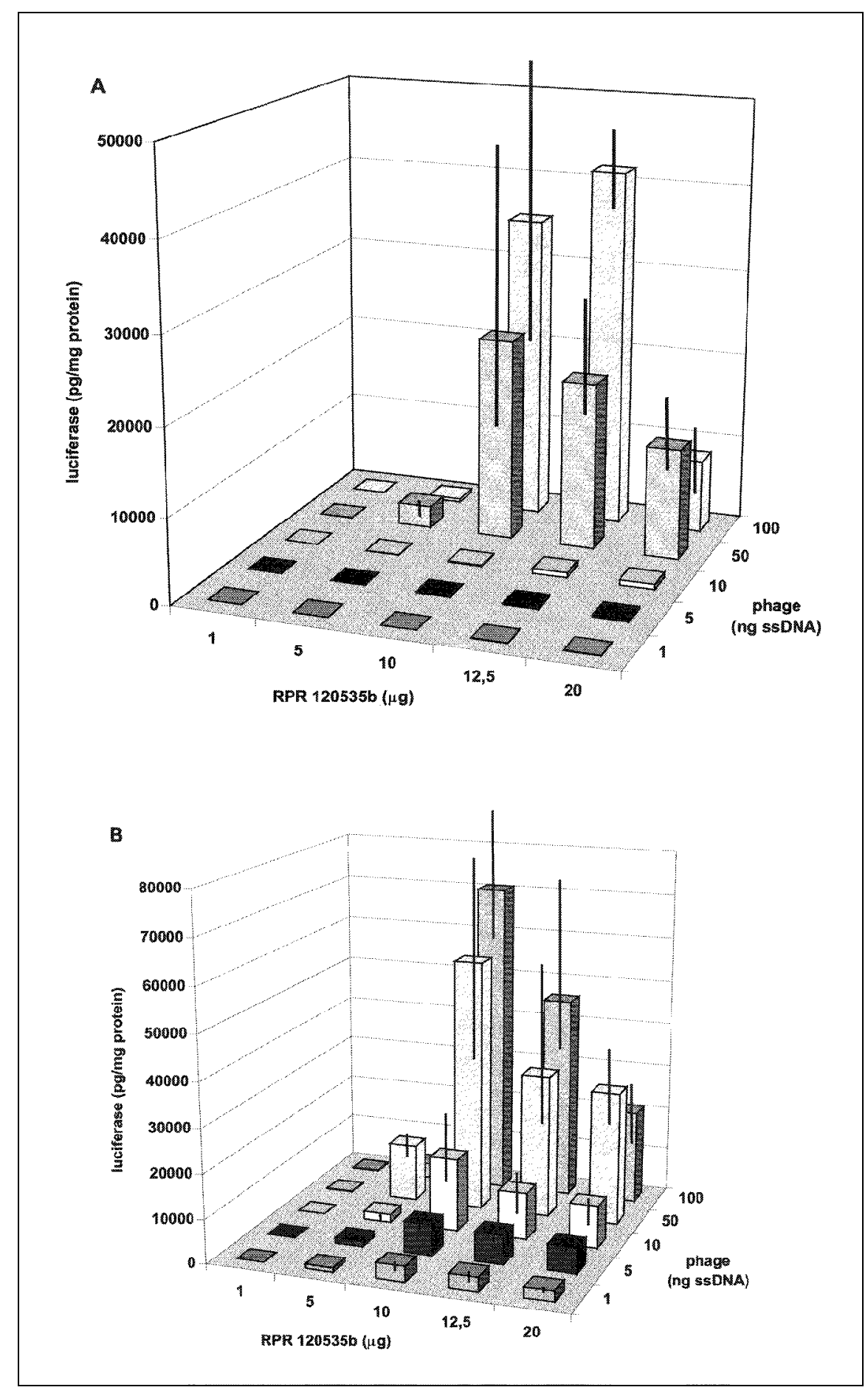

Figure 1. Response curves for CHO (A) and Cos-7 (B) cells. Cells were transfected in the presence of RPR120535b as described in the Materials and Methods section and analyzed for luciferase activity in a luminometer. Bars correspond to the average of three experiments and error bars to $95 \%$ confidence intervals. 
each coefficient is evaluated by a Student's t test (at a 95\% confidence level).

The lipid assessed by this approach was RPR120535b, which had given apparently the best initial results in $\mathrm{CHO}$ cells. The domain was initially estimated from previous phage vs. lipid experimental curves (see Results) (Figure 1). Extension to the adjacent domain was applied to CHO cells for which the optimum was found to lie outside the initial domain (Figure 2). In this particular case, to ensure better statistical validation, each point was repeated twice and the central point six times. Furthermore, in the experiment presented here, the two matrices were performed concurrently, and because of the complementarity of the domains, common experimental points were not repeated.

All calculations were carried out on the NEMROD software (16).

\section{RESULTS}

\section{Effect of Cationic Lipids on Transfection}

We first set out to confirm the results of Yokoyama-Kobayashi and Kato (32) with Transfectam in a standard response curve, which we then compared to those obtained with the structurally similar lipid, RPR120535b, and then extended to two other distinct lipids, TC1-12 and GAP-DLIRIE-DOPE (29). Results with
RPR120535b are presented in Figure 1 for both $\mathrm{CHO}$ and Cos-7 cells in terms of activity of luciferase/mg of protein/amount of phage DNA transfected (taking $1 \mathrm{ng}$ ssDNA as corresponding to approximately $3 \times 10^{8}$ phage) vs. quantity of lipid. Responses appear bell-shaped in relation to both amounts of lipid (optima between 5 and $15 \mu \mathrm{g}$ ) and phage (optima between 20 and $100 \mathrm{ng}$ DNA), as would be expected in this case $(9,11,32)$. For $\mathrm{CHO}$ cells, RPR120535b was found to be more efficient, while Transfectam was more efficient on Cos-7 cells (data not shown). Transfection efficiencies for the two other lipids were found to be much lower, by at least a factor of 10 , with TC112 faring the worst (data not shown).

\section{Optimization by Experimental Design}

Response curves of luciferase activity vs. amount of phage transfected (Figure 1) make it difficult to determine optimal conditions of transfection efficiency, and it became clear that there was no strict linear relationship with increasing lipid. To optimize transfection efficiency, we have used the approach of experimental design, which has rarely been used in such studies, but seems well suited for situations when there are clearly defined variables. Here, we have used a uniform shell matrix initially developed by Doehlert (8) in which the studied variables were limited to the amounts of lipid and phage such that the number of experimental points is 7 (with the central point being repeated three times for statistical evaluation). This approach is particularly useful to explore a domain in which a curvature may be expected. This method was applied to the transfection of phage into both $\mathrm{CHO}$ and Cos-7 cells in the presence of the lipid RPR120535b. Data obtained are given in Tables 1 and 2 and results presented in Figure 2, either as isoresponse curves (for $\mathrm{CHO}$ ) or as a three-dimensional (3-D) representation (for Cos-7).

The initial domain performed on $\mathrm{CHO}$ cells, and chosen based on the results of standard curves (Figure 1), analyzed transfection conditions between 1 and $20 \mu \mathrm{g}$ lipid and between 1 and 100 ng phage DNA. The $\mathrm{F}$ tests indicate that regression is significant $(P<0.0001)$ and that the polynomial model is statistically valid with regard to the estimated experimental error $(P=0.99)$. The $\mathrm{R}^{2}$ value is equal to 0.89 , which means that $89 \%$ of the variability of the response can be explained by the model. Also, none of the standardized residuals (Table 1) are over 2, which confirms that the model can predict the response for all the experimental conditions.

Nevertheless, as can be seen from Figure 2 A (isoresponse curves), optimal conditions are not found within this initial domain. Therefore, further
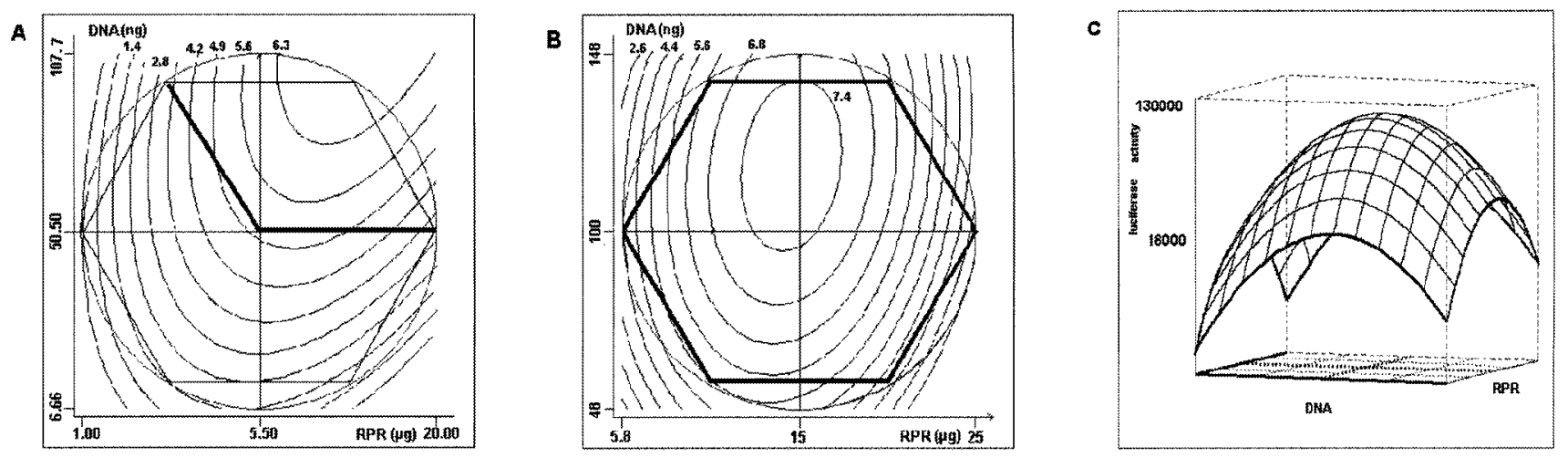

Figure 2. Isoresponse plot (A and B) and 3-D view (C) of luciferase activity (pg/mg of protein) as a function of input phage (DNA, ng) and cationic lipid $($ RPR120535b = RPR, $\mu \mathrm{g})$ in CHO $(\mathrm{A}=$ domain $1, \mathrm{~B}=$ domain 2$)$ and Cos-7 $(\mathrm{C})$ cells, respectively. The Doehlert matrices generated from the data of Tables 1 and 2 are shown in the isoresponse plots: (A) thin line for domain 1, (B) bold line for domain 2, with the common points between the two domains being indicated by the bold line in (A). Optimal conditions are found in the central circle of the contour plot. Values of luciferase expression are expressed in pg/mg protein $\left(\times 10^{4}\right)$ on the response curves. The 3-D view in (C) emphasizes the bell-shaped nature of the response. All plots were generated on the NEMROD software. 
Table 1. Doehlert Matrices for CHO Cells

\begin{tabular}{|c|c|c|c|c|c|c|}
\hline \multicolumn{7}{|c|}{ First Domain } \\
\hline & \multicolumn{2}{|c|}{ Doehlert design } & \multicolumn{2}{|c|}{ Experimental set } & \multicolumn{2}{|c|}{ Responses } \\
\hline & X1 & X2 & $\begin{array}{l}\text { RPR } \\
(\mu \mathrm{g})\end{array}$ & $\begin{array}{l}\text { phage } \\
\text { (ng) }\end{array}$ & $\begin{array}{l}\text { Luciferase activity } \\
\mathrm{pg} / \mathrm{mg} \text { protein }\end{array}$ & $\begin{array}{l}\text { Standardized } \\
\text { residuals }\end{array}$ \\
\hline 1 & 1 & 0 & 20 & 50.5 & $26742 / 33840$ & $-0.3956 / 0.3907$ \\
\hline 2 & -1 & 0 & 1 & 50.5 & $58.4 / 12$ & $0.005 /-0.0001$ \\
\hline 3 & 0.5 & 0.866 & 15.3 & 100 & $81000 / 56240$ & $1.3739 /-1.369$ \\
\hline 4 & -0.5 & -0.866 & 5.8 & 1 & $14660 / 13280$ & $0.074 /-0.0789$ \\
\hline 5 & 0.5 & -0.866 & 15.3 & 1 & $8740 / 9680$ & $-0.0496 / 0.0545$ \\
\hline 6 & -0.5 & 0.866 & 5.8 & 100 & $35140 / 31800$ & $0.1825 /-0.1875$ \\
\hline \multirow[t]{2}{*}{7} & 0 & 0 & 10.5 & 50.5 & $\begin{array}{c}48900 / 55760 / \\
36440\end{array}$ & $\begin{array}{c}-0.1388 / 0.6211 / \\
-1.5192\end{array}$ \\
\hline & & & & & $\begin{array}{c}56560 / 37980 / \\
65280\end{array}$ & $\begin{array}{c}0.7097 /-1.3486 / \\
1.6757\end{array}$ \\
\hline \multicolumn{7}{|c|}{ Second Domain } \\
\hline & \multicolumn{2}{|c|}{ Doehlert design } & \multicolumn{2}{|c|}{ Experimental set } & \multicolumn{2}{|c|}{ Responses } \\
\hline & $\mathrm{X} 1$ & $\mathrm{X} 2$ & $\begin{array}{l}\text { RPR } \\
(\mu \mathrm{g})\end{array}$ & $\begin{array}{l}\text { phage } \\
\text { (ng) }\end{array}$ & $\begin{array}{l}\text { Luciferase activity } \\
\mathrm{pg} / \mathrm{mg} \text { protein }\end{array}$ & $\begin{array}{l}\text { Standardized } \\
\text { residuals }\end{array}$ \\
\hline 1 & 1 & 0 & 24.8 & 100 & $37240 / 16180$ & $1.402 /-0.6621$ \\
\hline 2 & -1 & 0 & 5.8 & 100 & 35 140/31800 & $-0.2063 /-0.5336$ \\
\hline 3 & 0.5 & 0.866 & 20 & 149.5 & $64660 / 53480$ & $0.1779 /-0.9178$ \\
\hline 4 & -0.5 & -0.866 & 10.5 & 50.5 & $\begin{array}{l}48900 / 55760 / \\
56500 \\
37980 / 36440 / \\
65280\end{array}$ & $\begin{array}{l}0.0005 / 0.6728 / \\
0.7512 \\
-1.0698 /-1.2207 / \\
1.6059\end{array}$ \\
\hline 5 & 0.5 & 0.866 & 20 & 149.5 & $26742 / 33840$ & $-0.7178 /-0.0221$ \\
\hline 6 & -0.5 & 0.866 & 10.5 & 149.5 & $64740 / 67460$ & $0.2367 / 0.5033$ \\
\hline \multirow[t]{2}{*}{7} & 0 & 0 & 15.3 & 100 & $\begin{array}{c}81000 / 56240 / \\
57520\end{array}$ & $\begin{array}{c}1.6822 /-0.7445 / \\
-0.619\end{array}$ \\
\hline & & & & & $\begin{array}{c}57000 / 67420 / \\
131820^{a}\end{array}$ & $-0.67 / 0.3513$ \\
\hline \multicolumn{7}{|c|}{ aThis point was excluded from statistical evaluation. } \\
\hline \multicolumn{7}{|c|}{$\begin{array}{l}\text { Cells were transfected with the indicated amounts of lipid (RPR } 120535 \mathrm{~b}=\mathrm{RPR} \text { in } \mu \mathrm{g} \text { ) and phage (in ng ssDNA) and luciferase } \\
\text { activity measured at } 48 \mathrm{~h} \text { as described in Materials and Methods. The first domain was chosen on the basis of initial results } \\
\text { (Figure 1). It was then extended to the adjacent, second domain (see text for explanation) to identify optimal conditions. For the } \\
\text { second domain, values in bold represent the complementary experimental points performed. }\end{array}$} \\
\hline
\end{tabular}

experiments were performed on the adjacent domain (Table 1, second domain). This complementary matrix (Figure 2B) makes it possible to evaluate the response between 50.5 and $149.5 \mathrm{ng}$ phage DNA and between 5.8 and $25 \mu \mathrm{g}$ lipid. Statistical analysis gives an $\mathrm{R}^{2}$ value of 0.71 , the $\mathrm{F}$ tests show a significant regression $(P<$ $0.001)$ and a good fit of the polynomial model $(P=0.238)$. Moreover, none of the standardized residuals is higher than 1.68 (except for one of the six central points that, with a residual of 3.02, was excluded from the analysis). The equation describing the model is:

$$
\begin{aligned}
\hat{y}= & 638-7155 \cdot R P R+12185 \cdot D N A \\
& -33746 \cdot R P R^{2}-4489 \cdot D N A^{2} \\
& +8862 \cdot R P R \cdot D N A
\end{aligned}
$$

Both $\beta_{2}$ (DNA) and $\beta_{11}$ (square of lipid or curvature $)$ are significant $(P=0.001$ and $P=0.0001)$ and thus have an effect on the response. The curvature along the lipid axis can be easily seen on Figure 2B. Optimal conditions were now easily located in this second domain. The best set of conditions is found for about $15 \mu \mathrm{g}$ lipid and between 100 and 150 ng phage DNA. 
Table 2. Doehlert Matrix for Cos-7 Cells

\begin{tabular}{|c|c|c|c|c|c|c|}
\hline & \multicolumn{2}{|c|}{ Doehlert design } & \multicolumn{2}{|c|}{ Experimental set } & \multicolumn{2}{|c|}{ Responses } \\
\hline & $\mathrm{X} 1$ & $\mathrm{X} 2$ & $\begin{array}{l}\text { RPR } \\
(\mu \mathrm{g})\end{array}$ & $\begin{array}{c}\text { phage } \\
\text { (ng) }\end{array}$ & $\begin{array}{l}\text { Luciferase activity } \\
\mathrm{pg} / \mathrm{mg}\end{array}$ & $\begin{array}{l}\text { Standardized } \\
\text { residuals }\end{array}$ \\
\hline 1 & 1 & 0 & 20 & 50.5 & 45884 & 0.0222 \\
\hline 2 & -1 & 0 & 1 & 50.5 & 9632 & -0.0222 \\
\hline 3 & 0.5 & 0.866 & 15.3 & 100 & 56315 & -0.0222 \\
\hline 4 & -0.5 & -0.866 & 5.8 & 1 & 15366 & 0.0222 \\
\hline 5 & 0.5 & -0.866 & 15.3 & 1 & 31415 & -0.0222 \\
\hline 6 & -0.5 & 0.866 & 5.8 & 100 & 37793 & 0.0222 \\
\hline 7 & 0 & 0 & 10.5 & 50.5 & $\begin{array}{c}114190 / 128767 / \\
97888\end{array}$ & $\begin{array}{c}0.0456 / 1.2007 / \\
-1.2463\end{array}$ \\
\hline
\end{tabular}

Based on these results, we extended our analysis to Cos-7 cells with standard experimental conditions (i.e., the central point repeated three times and all other experimental points once). Results are given in Table 2 and shown in Figure $2 \mathrm{C}$ as a 3-D representation. While the power of statistical validation is reduced, to evaluate the model, we have limited ourselves to examining residuals (Table 2) and $\mathrm{R}^{2}$ (none of the standardized residuals is over 1.24 , and $\mathrm{R}^{2}$ explains $96 \%$ of the total variability). The equation that describes the model is now:

$$
\begin{array}{rl}
\hat{y}=1 & 13615+17846 \cdot R P R+13662 \\
& \cdot D N A-85857 \cdot R P R^{2}-75905 \\
& \cdot D N A^{2}+1428 \cdot R P R \cdot D N A
\end{array}
$$

Only the two square terms are significant $(P=0.001)$ and negative, explaining the bell-shaped curve represented in the 3-D contour plot (Figure 2C). The optimum is found to be situated around $10 \mu \mathrm{g}$ lipid and $50 \mathrm{ng}$ phage DNA.

To further test the models, we independently performed experimental points corresponding to both the optimum and conditions outside the domains. In the latter case, we tested the effect on efficiency of increasing amounts of optimal complex (i.e., at the optimal ratio of lipid to phage) on $\mathrm{CHO}$ cells. These experiments indicated that, at higher levels of the complex $(2 \times$ and $4 \times$ ), expression tended to fall from the optimum, in part because of the toxicity of the complex, as nearly half the cells died within $48 \mathrm{~h}$ at the $4 \times$ point (results not shown). We also tested transfection at $200 \mathrm{ng}$ phage DNA for $20 \mu \mathrm{g}$ lipid, which as expected gave a value below the optimum (results not shown).

\section{FACS Analysis}

We extended our analysis of transfection efficiency by assaying the activity of GFP by FACS analysis. Cells were transfected with phage (pM 40 carrying the gene for GFP) in the presence of either Transfectam or RPR120535b recovered after $48 \mathrm{~h}$ for FACS analysis under conditions of optimal transfection as determined above. Results suggest that up to $60 \%$ of Cos-7 cells are effectively transfected in the presence of Transfectam, and approximately 50\% with RPR120535b. With CHO cells, the data with Transfectam indicate that around $50 \%$ of cells display significant fluorescence but only $35 \%$ with RPR 120535 b. These results are in general conformity with expression levels.

\section{DISCUSSION}

We have confirmed that filamentous phage can be efficiently transfected into mammalian cells in the presence of cationic lipids. To confirm and extend the results obtained from standard response curves, we chose an approach based on experimental design, the
Doehlert matrix (which examined the influence of two variables, the amounts of lipid and phage) on transfection efficiency. While the former approach made it possible to localize initial domains of phage and lipid, we were interested in comparing the two strategies. Thus, a comparison of the results obtained by the two methodologies leads to the following conclusions. Standard response curves required 25 points, each repeated three times (i.e., 75 experiments). In contrast, with the latter approach, statistically valid optimal conditions may be obtained for two parameters with a set of 10 experiments covering seven data points generated over the same domain (this was achieved with Cos-7 cells). This not only means that all experiments can more easily be performed at the same time but also that the concomitant effect of other factors (e.g., cell preparation) can be neutralized.

Another advantage of the Doehlert matrix (which reduces the number of experiments to be performed) is its property of sequentiality. The initial rhombic shell domain that defines seven different experiments (for two parameters) can thus be completed by only four more experiments by using three of the results of the first shell to explore the adjacent domain. We have used this property in the case of $\mathrm{CHO}$ cells to find optimal conditions for the two factors analyzed, those not found in the first shell (Figure 2). In this case, we 
also observed a correct superposition of the response curves from the two shells, which tends to confirm the mathematical approach-more precise optimal conditions are generated by experimental design. In fact, some differences may be observed between the two approaches for both $\mathrm{CHO}$ and Cos7 cells (compare Figures 1 and 2). For example, for Cos-7 cells, the optimum from the standard curve may be taken to be $10 \mu \mathrm{g}$ RPR $120535 \mathrm{~b}$ and $100 \mathrm{ng}$ (or possibly more) phage DNA compared to $10 \mu \mathrm{g}$ and $50 \mathrm{ng}$, respectively, by experimental design.

While the model has been applied only to the analysis of transfection conditions of filamentous phage, it is clear that it can be applied to any other molecule, particularly DNA. In fact, because of the stacked nature of the phage coat, with charges mostly represented by the five exposed $\mathrm{N}$-terminal amino acids of
pVIII, present in 2700 copies (28), the interaction of cationic lipids with negatively charged amino acids of the coat is not too different from that with dsDNA.

It can be seen from the 3-D representation for Cos-7 cells (Figure 2C) that transfection follows a bell-shaped curve, which, in the case of Cos-7 cells, seems perfectly symmetrical around the optimal conditions. Of particular interest is the curvature observed along the lipid axis. This observation differs from that of Yokoyama-Kobayashi and Kato (32), but it should be noted that these workers did not examine the effect of Transfectam at doses higher than 12 $\mu \mathrm{g} /$ transfection, which is close to the optima observed, while we have examined up to $20 \mu \mathrm{g}$ where efficiency is definitively reduced (for Transfectam and RPR120535b) (results not shown). A possible explanation for this is related to the incapacity of the lipids to effi- ciently neutralize the charges on the surface of the phage at higher phage doses. However, if this were the only explanation, one would expect a plateau rather than a decline in efficiency. A more likely explanation is that this reduction is linked to the toxicity of the lipid or lipid-phage complex on cells. This is confirmed by experiments in which the quantity of the lipid-phage complex was increased per transfection. A decrease in transfection efficiency was observed at the higher doses, accompanied by a significant decrease in cell viability with increasing complex.

The relative effectiveness of cytofectins for $\mathrm{CHO}$ cells appears to be Transfectam = RPR120535b $>$ GAPDLRIE-DOPE $>$ TC1-12, while for Cos7 cells, the order is Transfectam> RPR120535b >>GAP-DLRIE-DOPE> TC1-12. For both cell lines, TC1-12, which only carries one positive charge 
per molecule, gives the lowest efficiency of transfection. Since association of phage with lipid, as with DNA, is a matter of charge ratio, it seemed reasonable to assume that by augmenting the ratio of TC1-12/phage, one would compensate for the lack of charges on the lipid. In fact, this is not the case because of the toxicity of the lipid complex to the cells (results not shown). Transfectam and RPR120535b both have very similar structures (5), and each bears four charges, while GAP-DLRIE-DOPE has two positive charges (29). This suggests that efficiency is at least in part related to the number of charges on the lipid, secondarily to its structure.

\section{ACKNOWLEDGMENTS}

Work described here by C. Droy and D. Seguin was performed as part of their requirement for a degree in "Cell and tissue culture" from the Université de Bourgogne-Institut Universitaire de Technologie (Dijon, France). We also acknowledge the help of N. Devard. We thank N. Pascal and Yves GirerdChambaz for help in FACS analysis and transfection assays, respectively, Daniel Scherman (RPR/GENCELL) for RPR120535b and Anne Broudiscou (LPRAI) for critical comments on the manuscript.

\section{REFERENCES}

1.Aujame, L., R. Sodoyer and F. Geoffroy. 1997. High affinity human antibodies by phage display. Hum. Antibodies 8:155-168.

2.Barry, M.A., W.J. Dower and S.A. Johnston. 1996. Toward cell-targeting gene therapy vectors: selection of cell-binding peptides from random peptide-presenting phage libraries. Nat. Med. 2:299-305.

3.Boleda, M.D., P. Briones, J. Farrès, L. Tyfield and R. Pi. 1996. Experimental design: a useful tool for PCR optimization. BioTechniques 21:134-140.

4.Box, G.E.P., W.G., Hunter and J.S. Hunter. 1978. Statistics for Experimenters. John Wiley $\&$ Sons, New York.

5.Byk, G., C. Dubertret, V. Escriou, M. Frederic, G. Jaslin, R. Rangara, B. Pitard, J. Crouzet et al. 1998. Synthesis, activity and structure-activity relationship studies of novel cationic lipids for DNA transfer. J. Med. Chem. 41:224-235.

6.Carter, C.W., Jr. 1990. Efficient factorial designs and the analysis of macromolecular crystal growth conditions. Methods I:12-24.
7.Cobb, B.D. and J.M. Clarkson. 1994. A simple procedure for optimising the polymerase chain reaction (PCR) using modified Taguchi methods. Nucleic Acids Res. 22:3801-3805.

8.Doelhert, D.H. 1970. Uniform shell designs. Appl. Stat. 19:231-239.

9.Felgner, P., T.R. Gadek, M. Holm, R. Roman, H.W. Chan, M. Wenz, J.P. Northrop, G.M. Ringold and M. Danielsen. 1987. Lipofection: a highly efficient, lipid-mediated DNA-transfection procedure. Proc. Natl. Acad. Sci. USA 84:7413-7417.

10.Ganne, V. and G. Mignot. 1991. Application of statistical design of experiments to the optimization of factor VIII expression by $\mathrm{CHO}$ cells. Cytotechnology 6:233-240.

11.Gao, X. and L. Huang. 1991. A novel cationic liposome reagent for efficient transfection of mammalian cells. Biochem. Biophys. Res. Commun. 179:280-285.

12.Gluzman, Y. 1981. SV40-transformed simian cells support the replication of early SV40 mutants. Cell 23:175-182.

13.Hoogenboom, H.R. 1997. Designing and optimizing library selection strategies for generating high affinity antibodies. Trends Biotechnol. 15:62-70.

14.Krause, R.D. and J.A. Lott. 1974. Use of the simplex method to optimize analytical conditions in clinical chemistry. Clin. Chem. 20:775-782.

15.Larocca, D., A. Witte, W. Johnson, G.F. Pierce and A. Baird. 1999. Targeting bacteriophage to mammalian cell surface receptors for gene delivery. Hum. Gene Ther. 9:23932399.

16.Mathieu, D. and R. Phan-Tan-Luu. 1981 NEMROD: New Efficient Methodology for Research using Optimal Design. L.P.R.A.I. Université d'Aix-Marseille.

17.Messing, J., B. Gronenborg, B. Muller-Hill and P.H. Hofschneider. 1977. Filamentous coliphage M13 as cloning vehicle: insertion of a HindII fragment of the lac regulatory region in M13 replicative form in vitro. Proc. Natl Acad. Sci. USA 74:3642-3646.

18.Murphy, T.D. 1977. Design and analysis of industrial results. Chem. Eng. 6:169-182.

19.Pasqualini, R.E. and E. Ruoslahti. 1996. Organ targeting in vivo using phage display peptide libraries. Nature 380:364-366.

20.Rader, C. and C.F. Barbas III. 1997. Phage display of combinatorial antibody libraries. Curr. Opin. Biotechnol. 8:503-508.

21.Rautela, G.S., R.D. Snee and W.K. Miller. 1979. Response surface co-optimization for reaction conditions in clinical chemical methods. Clin. Chem. 25:1954-1964.

22.Rider, J.E., A.B. Sparks, N.B. Adey and B.K. Kay. 1996. Microbiological methods, p. 55-66. In B.K. Kay, J. Winter and J. McCafferty (Eds.), Phage Display of Peptides and Proteins. Academic Press, San Diego.

23.Rubin, I.B., T.J. Mitchell and G. Goldstein. 1971. A program of statistical designs for optimizing specific transfer ribonucleic acid assay conditions. Anal. Chem. 43:717-772.

24.Russell, S.J. 1996. Peptide-displaying phages for targeted gene delivery? Nat. Med. 2:276277.

25.Slowe R.A. and R.P. Mayer. 1966. Efficient screening of process variables. Ind. Eng.
Chem. 2:36-40

26.Smith, G.P. 1985. Filamentous fusion phage: novel expression vectors that display cloned antigens on the virion surface. Science 228:1315-1317.

27.Urlaub, G. and L.A. Chasin. 1980. Isolation of Chinese hamster cell mutants deficient in dihydrofolate reductase activity. Proc. Natl. Acad. Sci. USA 77:4216-4220.

28.Webster, R.E. 1996. Biology of filamentous bacteriophage, p. 1-20. In B.K. Kay, J. Winter and J. McCafferty (Eds.), Phage Display of Peptides and Proteins. Academic Press, San Diego.

29.Wheeler, C.J., P.L. Felgner, Y.J. Tsai, J. Marshall, L. Sukhu, S.G. Doh, J. Hartikka, J. Nietupski et al. 1996. A novel cationic lipid greatly enhances plasmid DNA delivery and expression in mouse lung. Proc. Natl. Acad. Sci. USA 93:11454-11459.

30. Yin, Y. and C.W. Carter Jr. 1996. Incomplete factorial and response surface methods in experimental design: yield optimization of tRNA (Trp) from in vitro T7 RNA polymerase transcription. Nucleic Acids Res. 24:12791286

31.Yokoyama-Kobayashi, M. and S. Kato. 1993. Recombinant f1 phage particles can transfect monkey COS7 cells by DEAE dextran method. Biochem. Biophys. Res. Commun. 192:935-939.

32.Yokoyama-Kobayasi, M. and S. Kato. 1994. Recombinant $\mathrm{f} 1$ phage-mediated transfection of mammalian cells using lipopolyamine technique. Anal. Biochem. 223:130-134.

Received 14 July 1999; accepted 3 January 2000.

Address correspondence to:

Dr. Luc Aujame

Dept. of Molecular Biology

Aventis Pasteur

1541 Ave. Marcel Mérieux

69280 Marcy L'Etoile, France

Internet:luc.aujame@aventis.com 